\title{
Risk of injury and the consumption of different types of beverage: Is there an association?
}

\author{
E Plugge, L Fletcher, S Stewart-Brown
}

The health benefits of moderate consumption and the damaging consequences of excessive consumption of alcohol are well documented. ${ }^{1}$ Injury is an important alcohol related health problem but while the role of alcohol in particular types of injury has been studied, ${ }^{2}$ there is little information on particular types of alcoholic beverage and injuries. This contrasts with the literature on cardiovascular disease and alcohol where the relation with the consumption of different beverages has been extensively explored. The evidence here indicates that there is no specific benefit associated with one type of beverage; the extra benefit associated with wine in some studies can be explained by different drinking patterns. ${ }^{1}$

We looked at data from a community survey to explore for the first time, the relation between the risk of non-fatal injury and the consumption of particular types of beverage.

\begin{tabular}{|c|c|c|}
\hline & \multicolumn{2}{|l|}{ Methods } \\
\hline & \multicolumn{2}{|c|}{ We analysed data obtained from the 1997} \\
\hline & \multicolumn{2}{|c|}{ Oxford Healthy Lifestyle Survey. ${ }^{3}$ This was } \\
\hline & \multirow{2}{*}{\multicolumn{2}{|c|}{$\begin{array}{l}\text { carried out on a sample of } 18-64 \text { year olds ran- } \\
\text { domly selected from the computerised general }\end{array}$}} \\
\hline & & \\
\hline & \multicolumn{2}{|c|}{ practitioner records for Berkshire, Bucking- } \\
\hline & \multicolumn{2}{|c|}{$\begin{array}{l}\text { hamshire, Northamptonshire and Oxfordshire } \\
\text { in England. A } 20 \text { page questionnaire on }\end{array}$} \\
\hline & \multirow{2}{*}{\multicolumn{2}{|c|}{ lifestyle and health service use was mailed to }} \\
\hline Health Services & & \\
\hline Research Unit, & \multirow{4}{*}{\multicolumn{2}{|c|}{$\begin{array}{l}\text { previous year and about the amount and type } \\
\text { of alcohol drunk in the past week. The survey } \\
\text { achieved a corrected response rate of } 64 \%\end{array}$}} \\
\hline University of Oxford, & & \\
\hline Institute of Health & & \\
\hline Sciences, Oxford, UK & & \\
\hline $\begin{array}{l}\text { Correspondence to: } \\
\text { Emma Plugge, } \\
\text { (emma.plugge@ } \\
\text { epublichealth.org.uk) }\end{array}$ & \multicolumn{2}{|c|}{$\begin{array}{l}\text { (8889 of } 13800) \text {. Women and those aged } \\
55-64 \text { years were slightly over-represented in } \\
\text { the sample. } \\
\text { Data were analysed using SPSS version 9.0. }\end{array}$} \\
\hline Accepted for publication & \multicolumn{2}{|c|}{ The annual incidence rate of injury was calcu- } \\
\hline 27 June 2001 & \multicolumn{2}{|c|}{ lated with $95 \%$ confidence intervals and } \\
\hline \multicolumn{3}{|c|}{$\begin{array}{l}\text { Table } 1 \text { The risk of injury and the type of beverage consumed. Adjusted and unadjusted } \\
\text { data }\end{array}$} \\
\hline & \multicolumn{2}{|c|}{ Risk of injury requiring medical attention in past year } \\
\hline Type of beverage consumed & $\begin{array}{l}\text { Unadjusted odds ratio (95\% } \\
\text { confidence intervals) }\end{array}$ & $\begin{array}{l}\text { Adjusted odds ratio* } \\
\text { confidence intervals) }\end{array}$ \\
\hline Alcopops & $1.47(1.16$ to 1.85$)$ & 1.30 \\
\hline & $=76$ & \\
\hline $\mathrm{Be}$ & $1.59(1.40$ & 1.1 \\
\hline $\mathrm{n}=844$ & $\mathrm{~N}=7592$ & $\mathrm{~N}=7491$ \\
\hline Sherry or fortified wine & $0.92(0.75$ to 1.14$)$ & $1.11(0.89 t$ \\
\hline $\mathrm{n}=113$ & (0.1) & \\
\hline Spirits & $1.08(0.95$ & 1.11 \\
\hline $\mathrm{n}=403$ & $\mathrm{~N}=7598$ & $\mathrm{~N}=7497$ \\
\hline Wine & 0.81 (0.72 to 0.92$)$ & $0.93(0.82$ to 1.05$)$ \\
\hline $\mathrm{n}=690$ & $\mathrm{~N}=7597$ & $\mathrm{~N}=7496$ \\
\hline
\end{tabular}

Research Unit, University of Oxford, Institute of Health Sciences, Oxford, UK

Correspondence to: Emma Plugge,

(emma.plugge@

epublichealth.org.uk)

Accepted for publication 27 June 2001

Table 1 The risk of injury and the type of beverage consumed. Adjusted and unadjusted data

*Adjusted for age, sex and number of units consumed. $\mathrm{N}=$ total number of subjects analysed (both drinkers of that beverage and subjects who do not drink that beverage). $n=$ number of subjects injured (drinkers of that particular beverage).
KEY POINTS

- Accidents are an important public health problem and the literature shows that people who consume alcohol are more likely to injure themselves than those who abstain.

- In contrast to cardiovascular disease, there is no information on the relation between the risk of non-fatal injury and the consumption of particular types of beverage.

- Our study shows that different accident rates between groups of drinkers of different beverages are attributable to differences in age, sex and the amount consumed rather than any intrinsic quality of the beverage.

analysed according to the type of alcohol consumed. Logistic regression analysis was performed by a forward stepwise method using the possible confounding variables of age, gender and units of alcohol drunk in the past week.

\section{Results}

Sixteen per cent of all respondents reported an injury requiring medical attention in the previous 12 months. Those who drank any alcohol were significantly more likely to report being injured than those who abstained (16.4\% versus $\left.12.5 \%, \chi^{2}=11.26, p=0.0008\right)$. Those who drank wine were less likely to have been injured than those drinking other beverages $\left(15.3 \%\right.$ versus $\left.18.1 \%, \chi^{2}=10.53, p=0.001\right)$, and those who drank beer or alcopops were more likely to report being injured (18.9\% versus $12.8 \%, \chi^{2}=49.8, p=0.00000$ and $21.9 \%$ versus $\left.16.1 \%, \chi^{2}=10.58, \mathrm{p}=0.001\right)$. No differences were seen for sherry and spirit drinkers.

Logistic regression revealed that when age, sex and amount of alcohol had been controlled for, there were only significant differences in the risk of injury for drinkers of beer or alcopops, although the added risk was small (odds ratios 1.17 (95\% confidence intervals 1.01 to 1.36$)$ and 1.30 (1.02 to 1.66$)$ respectively) (table 1 ).

\section{Discussion}

While confirming the association between alcohol use and accidental injury shown in many other studies, ${ }^{4}$ this study is the first to look specifically at the relation between different beverages and all types of non-fatal injury that have required medical attention. Our findings indicate that there is a relation between the type of beverage drunk and the likelihood of injury but that this probably is not because of any intrinsic quality of the beverage. Rather it 
can largely be explained by sex and age differences between groups of drinkers, and the amount of alcohol consumed. It would be interesting to examine whether the pattern of drinking affected the risk of injury and accounted for the slight increase in beer and alcopop drinkers, but no such data were available from the survey. People are more likely to be injured when acutely intoxicated ${ }^{4}$ and beer and alcopop drinkers may be more inclined to "binge" drink.

We acknowledge that there are certain limitations to our study because the data on alcohol consumption relate to a time period which is after the occurrence of the injury. However, as the great majority of injuries requiring medical attention had no lasting consequences, it is unlikely that alcohol consumption is affected by the experience of injury.

Studies examining the behavioural effects of different beverages show that differences between beer, wine and spirit drinkers in alcohol related problems such as drink driving, can be attributed to the differences in the age and sex of the drinker and how much and how often they drink. ${ }^{5}$ The results of our study, while looking at a different outcome, concur with these findings and reinforce the need to reduce alcohol consumption as part of any injury prevention strategy.

This study could not have been undertaken without the contribution of Sophie Petersen who collected the data for the survey.

Funding: the Health Services Research Unit is largely funded by the NHS Executive (South East). Emma Plugge is paid by the NHS training budget.

Conflicts of interest: none.

1 Doll R. One for the heart. BMf 1997;315:1664-8.

2 Lowenfels AB, Miller T. Alcohol and trauma. Ann Emerg Med 1984;13:1056-60.

3 Petersen S, Stewart-Brown S, Peto V. Health and lifestyles in the Four Counties. Oxford: Health Services Research Unit, Department of Public Health and Primary Care: University of Oxford, 1998.

4 Glucksman E. Alcohol and accidents. Br Med Bull 1994;50: $76-84$

5 Smart RG. Behavioral and social consequences related the consumption of different beverage types. I Stud Alcohol 1996;57:77-84.

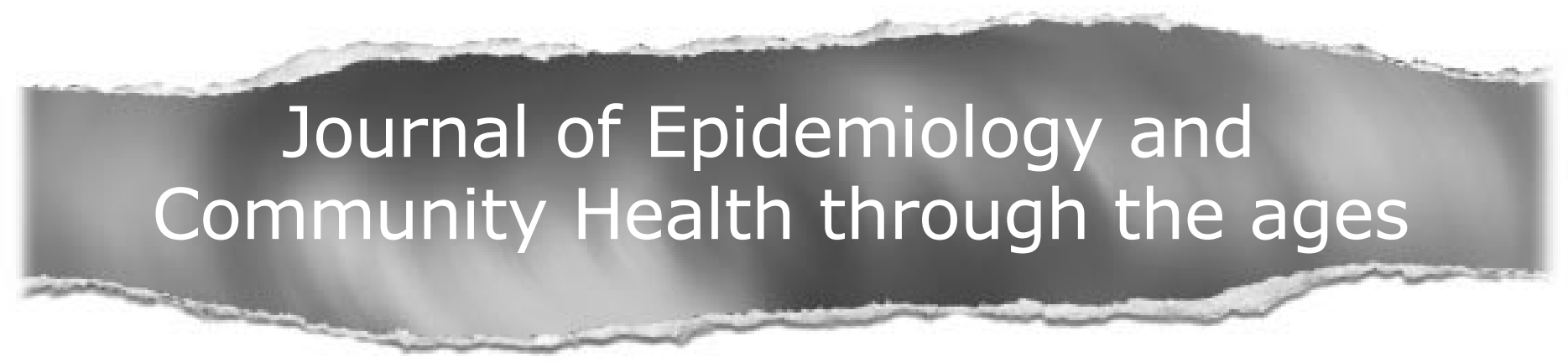

Browse the Archive

Journal of Epidemiology and Community Health online has an archive of content dating back to 1978. Full text from January 2000; abstracts from 1978; table of contents from 1978

www.jech.com 